\title{
Necrosectomy of hepatic left lateral section after blunt abdominal trauma in a patient who underwent central hepatectomy and bile duct resection for perihilar cholangiocarcinoma
}

\author{
Seul Gi Oh, Shin Hwang, Suhyeon Ha, Heewon Kim, and Lee Na Ryu \\ Department of Surgery, Asan Medical Center, University of Ulsan College of Medicine, Seoul, Korea
}

\begin{abstract}
When the liver is divided into the right and left halves after central hepatectomy, a serious injury to the one half of the liver can destroy the ipsilateral half. We report a case showing total necrosis of the hepatic left lateral section (LLS) caused by blunt abdominal trauma in a patient who had undergone central hepatectomy and bile duct resection for perihilar cholangiocarcinoma. A 47-year-old female patient was transferred because of postoperative status following blunt abdominal trauma. Five years before, she had been diagnosed with perihilar cholangiocarcinoma. Since the tumor extent was compatible with Bismuth-Corlette type IV, she underwent central hepatectomy and bile duct resection. After five years, she experienced an industrial safety accident, in which a heavy refrigerator fell over her body. She underwent emergency duodenal diversion surgery with distal gastrectomy and Roux-en-Y gastrojejunostomy. During this surgery, serious ischemic injury of the LLS with occlusion of the left portal vein and hepatic artery was identified, but not treated. After three weeks, LLS necrosectomy with repair of the jejunal limb was done. Postoperative bile leak developed and required supportive care for two months for its healing. She is currently doing well without any physical discomfort four months after the necrosectomy. Our experience with this case suggests that an injury to the afferent jejunal limb requires an individualized treatment strategy including long-standing waiting with effective drainage for spontaneous healing. The experience of this case appears to be theoretically matched with late-stage resection of LLS following central hepatectomy and bile duct resection. (Ann Hepatobiliary Pancreat Surg 2020;24:345-351)
\end{abstract}

Key Words: Central hepatectomy; Abdominal trauma; Bile leak; Cholangiocarcinoma; Necrosis

\section{INTRODUCTION}

The human liver is a single integrated organ, but its segmental anatomy enables it to be divided into hemilivers, sections, and segments. When the liver is divided in half, the right and left halves, after central hepatectomy, ${ }^{1-3}$ a serious injury to half can destroy the ipsilateral half. If the function of the contralateral half is preserved, the patient's life can be saved. A similar situation was uniquely observed in dual-graft living-donor liver transplantation, in which one liver graft did not work because of serious vascular complications. ${ }^{4,5}$

We herein report a case showing total necrosis of the hepatic left lateral section (LLS) because of blunt abdominal trauma in a patient who had undergone central hepatectomy and bile duct resection for perihilar cholangio- carcinoma. We describe the detailed sequences of the treatment process because our experience in this case appears to be theoretically matched with late-stage resection of LLS following central hepatectomy.

\section{CASE}

A 47-year-old female patient was transferred because of postoperative status following blunt abdominal trauma. Five years before, she had been diagnosed with perihilar cholangiocarcinoma. Since the tumor extent was compatible with Bismuth-Corlette type IV (Fig. 1), she underwent central hepatectomy and bile duct resection. The extent of the hepatectomy included segment IV, the medial portions of segments V and VIII, and segment I; thus the right and left halves of the liver were completely sepa-

Received: June 13, 2020; Revised: June 22, 2020; Accepted: June 22, 2020

Corresponding author: Shin Hwang

Department of Surgery, Asan Medical Center, University of Ulsan College of Medicine, 88 Olympic-ro 43-gil, Songpa-gu, Seoul 05505, Korea Tel: +82-2-3010-3930, Fax: +82-2-3010-6701, E-mail: shwang@amc.seoul.kr

Copyright (C) 2020 by The Korean Association of Hepato-Biliary-Pancreatic Surgery

This is an Open Access article distributed under the terms of the Creative Commons Attribution Non-Commercial License (http://creativecommons.org/ censes/by-nc/4.0) which permits unrestricted non-commercial use, distribution, and reproduction in any medium, provided the original work is properly cited. Annals of Hepato-Biliary-Pancreatic Surgery - pISSN: 2508-5778 - elSSN: 2508-5859 


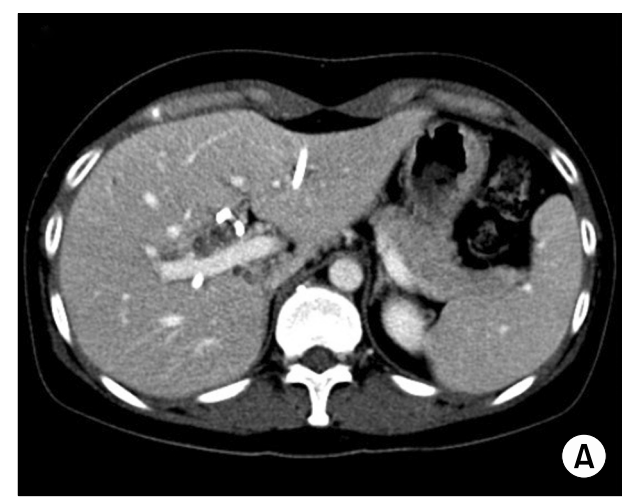

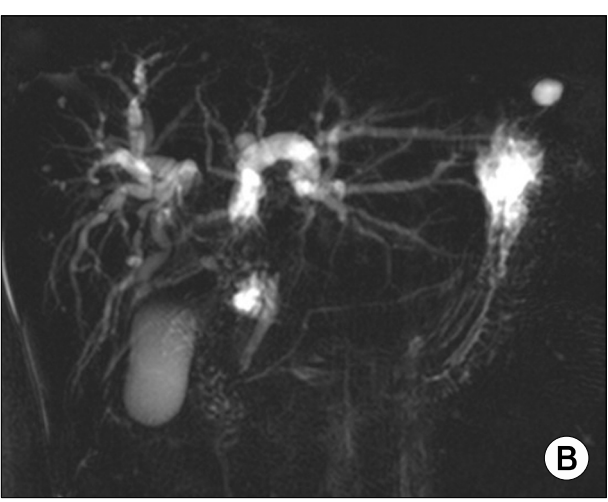

B
Fig. 1. Initial preoperative radiologic findings. The computed tomography scan showed perihilar cholangiocarcinoma (A). Magnetic resonance cholangiopancreatography showed an intraluminal mass involving the right and left hepatic ducts (B).
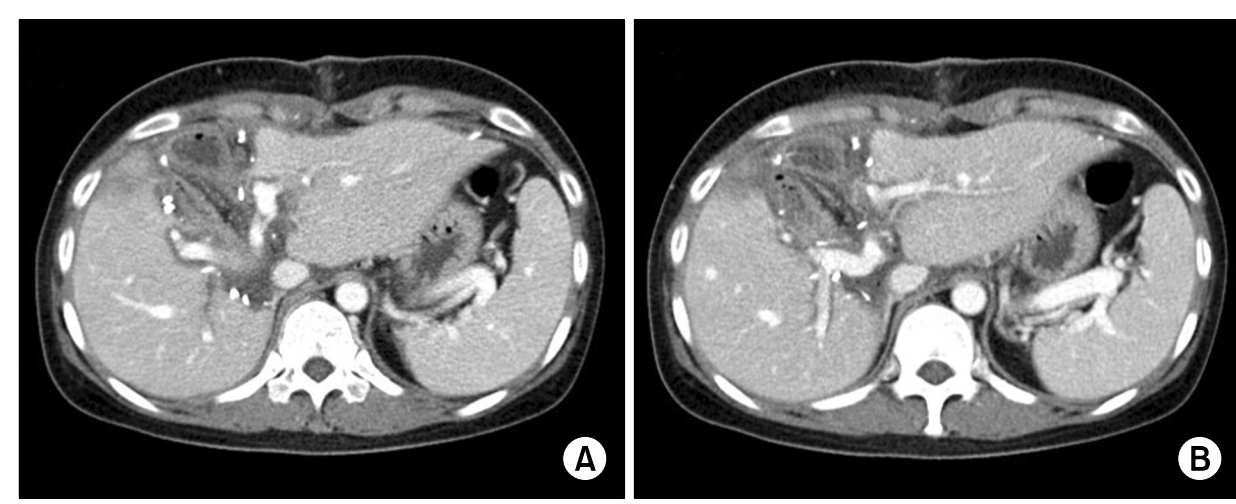

Fig. 2. Postoperative radiologic findings taken at one week after central hepatectomy and bile duct resection. The computed tomography scan showed that the medial portion of the right anterior section was resected (A). Biliary reconstruction and intervening jejunal limb is visible (B).

rated (Fig. 2). There were three separate bile duct openings of segments VI+VII (B6+7), V (B5), and VIII (B8) at the right half, and one opening of segment II+III $(\mathrm{B} 2+3)$ at the left half. The resection margins of these four bile duct openings were tumor-negative on frozen section biopsies. The B5 and B8 were unified to make one opening. Two separate hepaticojejunostomies were done to the $\mathrm{B} 5+\mathrm{B} 8$ and $\mathrm{B} 67$ at the right half and one hepaticojejunostomy was done to the $\mathrm{B} 2+3$ at the left half. The intervening jejunal portion between these right- and left-side biliary reconstruction sites was redundant, being approximately $10 \mathrm{~cm}$ in length.

The pathology report presented a $4.1 \mathrm{~cm}$-sized well-differentiated cholangiocarcinoma of papillary type (Fig. 3). There was lymphovascular invasion with absence of perineural invasion. There was lymph node metastasis in 1 of 15 lymph nodes. Postoperatively, she underwent concurrent chemoradiation therapy and adjuvant chemotherapy. She has undergone follow-up imaging studies regularly (Fig. 4) and no tumor recurrence developed up to five years after surgery.

Just after five years, she experienced an industrial safety accident, in which a heavy refrigerator fell over her

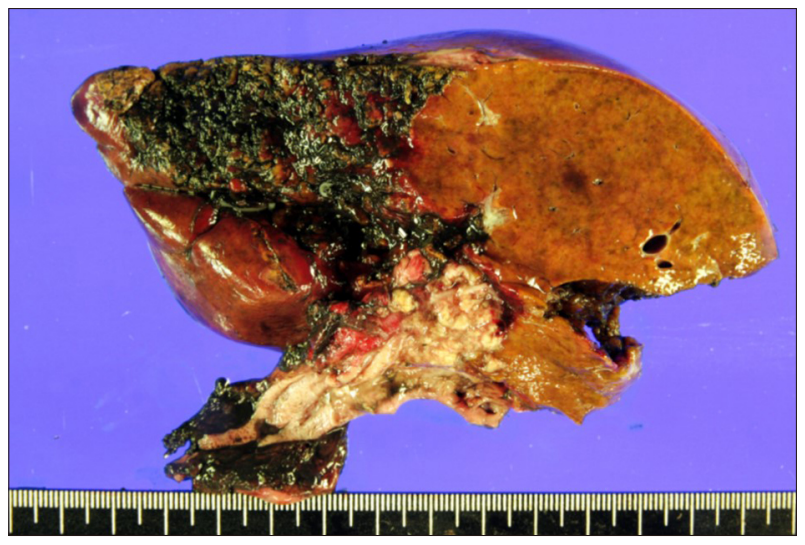

Fig. 3. Gross photographs of the resected specimen showing well-differentiated cholangiocarcinoma of papillary type.

body. She visited the emergency room at a nearby community hospital and was diagnosed with blunt abdominal trauma to the duodenum and left liver. She underwent emergency duodenal diversion surgery with distal gastrectomy and Roux-en-Y gastrojejunostomy. During this surgery, the surgeons identified serious ischemic injury of the LLS with occlusion of the left portal vein and hepatic artery, but they did not do any surgical treatment for liver injury, primarily because there was no active bleeding. 

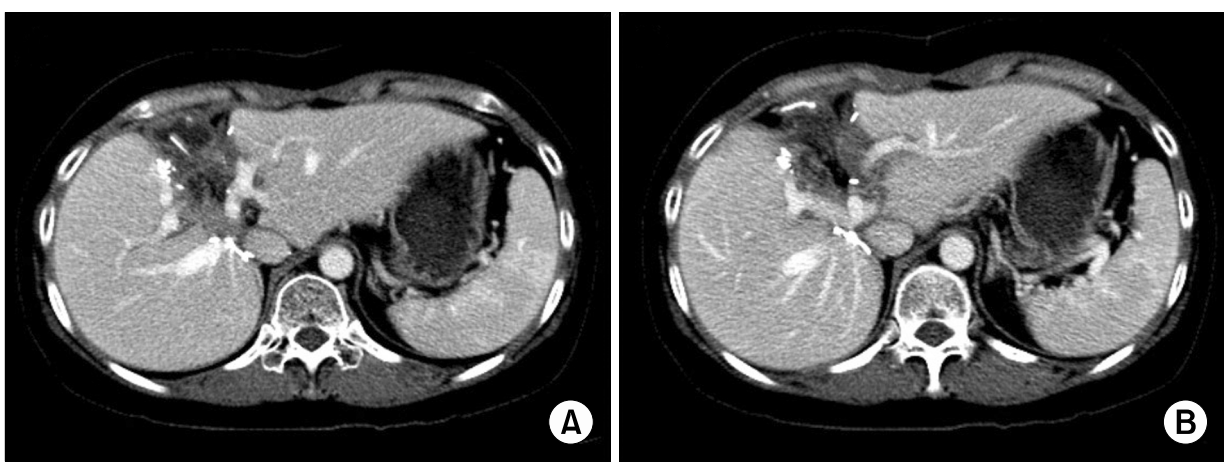

Fig. 4. Postoperative radiologic findings taken at two years after the central hepatectomy and bile duct resection. The computed tomography scan showed no bile duct dilatation at the right (A) and left (B) liver parts.

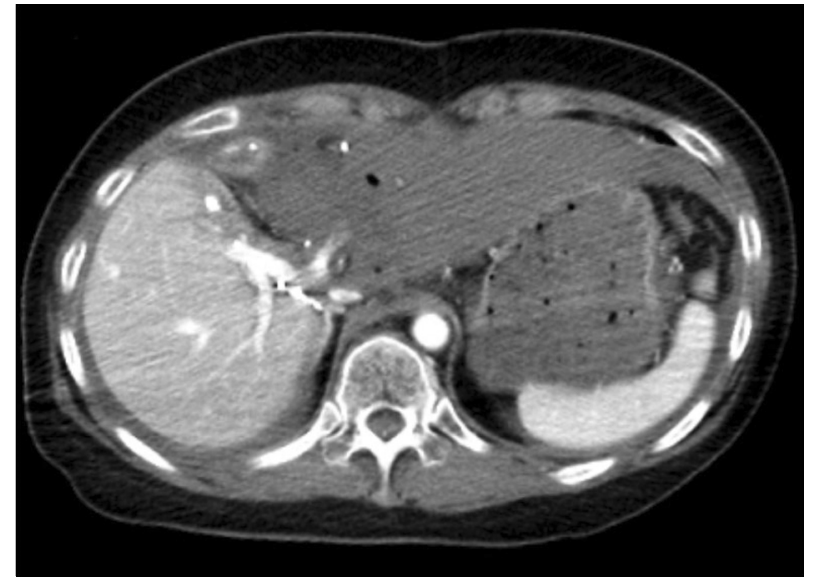

Fig. 5. Radiologic finding showing complete ischemic necrosis of the left lateral section soon after blunt abdominal trauma.

At two weeks after the abovementioned emergency operation, she was transferred to our institution for treatment of liver injury. Pure bile was drained from an abdominal drain inserted during the emergency operation. Dynamic abdomen computed tomography (CT) revealed that there was no blood flow at the LLS, indicating total ischemic necrosis (Fig. 5). Magnetic resonance cholangiopancreatography showed a massive bile leak at the afferent jejunal limb (Fig. 6). After a thorough workup for a week, we decided to perform necrosectomy of the necrotic LLS, because there was no possibility of spontaneous resolution of the LLS necrosis, which could have become a source of life-threatening infection.

After laparotomy, the necrotic materials filling the LLS space were gently removed and the occluded intrahepatic vascular stumps were exposed (Fig. 7A, B). These vascular structures were ligated or sutured securely to prevent potential bleeding (Fig. 7C). We tried to identify the hepaticojejunostomy site of the LLS, but failed because it ap-

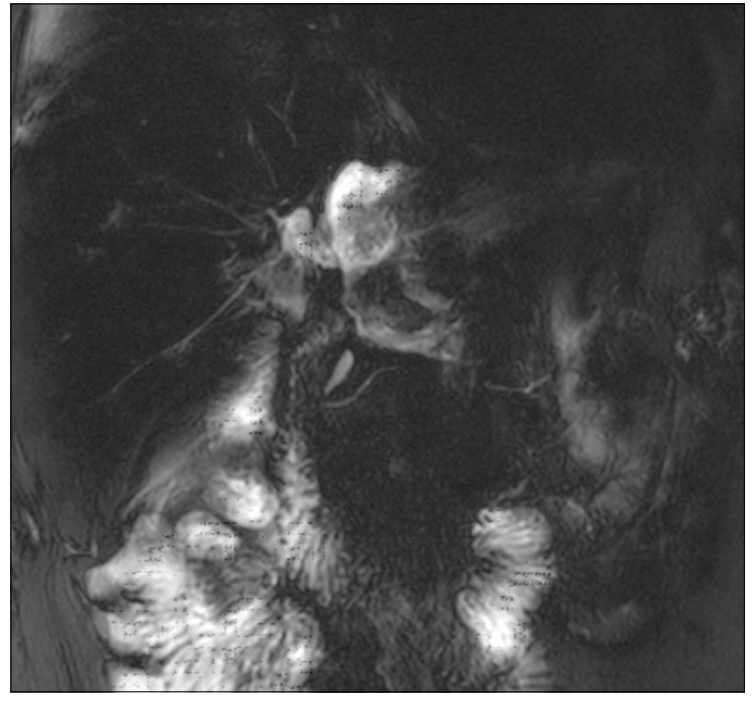

Fig. 6. Magnetic resonance cholangiopancreatography showed massive bile leak at the afferent jejunal limb.

peared to be widely disrupted and heavily adhered to the adjacent structures. To identify the injury site where the intervening jejunal limb was disrupted, we performed a frozen-section biopsy using the exposed wall of uncertain luminal structures, which was pathologically diagnosed with small bowel mucosa. Matching with the preoperative imaging study findings, we presumed that the intervening jejunal limb between the right liver and LLS were disrupted.

Our next step was injection of indocyanine green solution into the afferent jejunal limb close to the jejunojejunostomy after temporary clamping of the jejunojejunostomy (Fig. 7D). The injected dye solution was leaked from the injured portion of the intervening jejunal limb, which indicated the location of bowel wall repair. The injured wall of the intervening jejunal limb was meticulously repaired with multiple primary sutures and securely covered with absorbable mesh and fibrin glue. We 

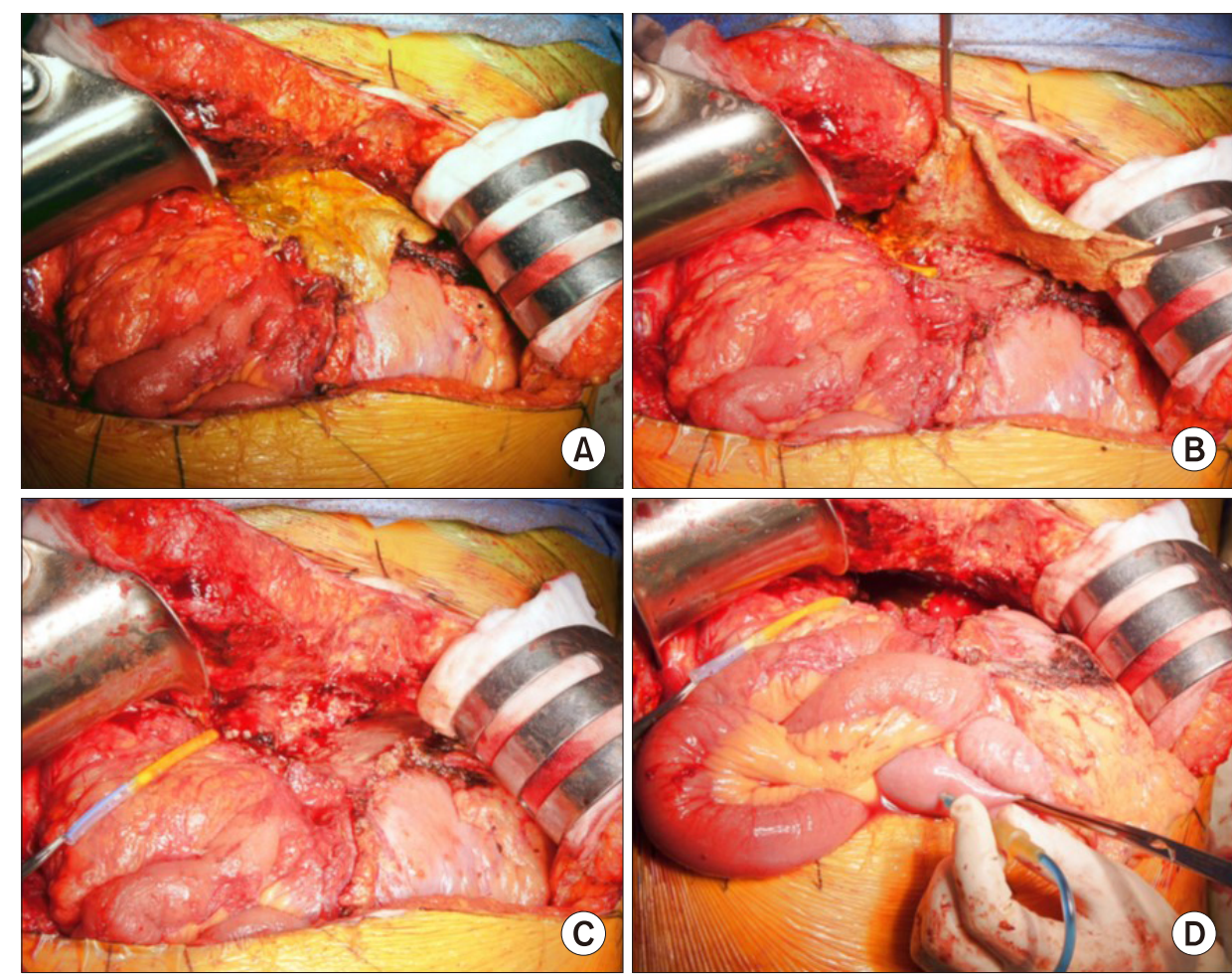

Fig. 7. Gross photographs of the surgical procedure for necrosectomy. Necrotic materials filling the left lateral section space were gently removed (A and B). Intrahepatic vascular structures were ligated (C). Dye solution was injected into the afferent jejunal limb after temporary clamping of the jejunojejunostomy (D).

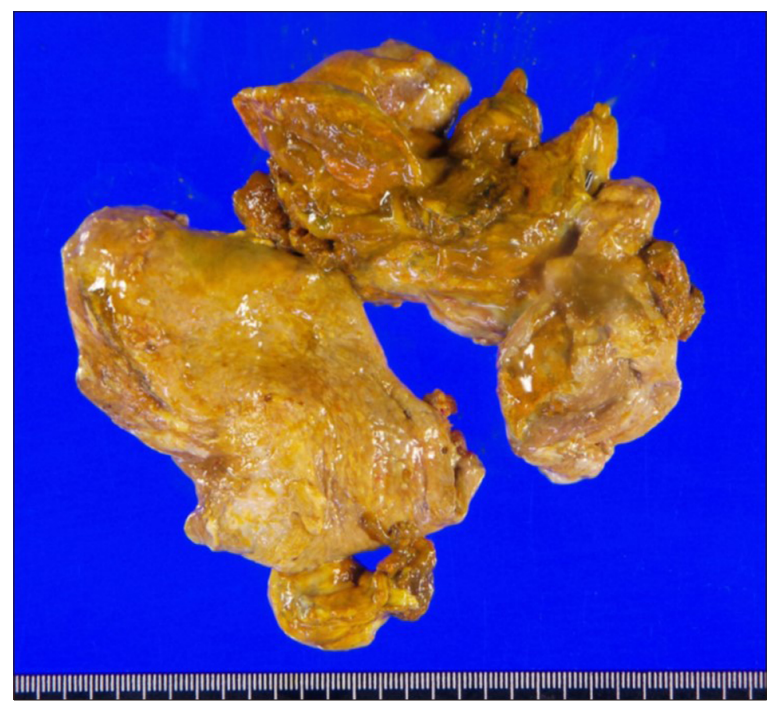

Fig. 8. Gross photographs of the resected liver specimen showing complete necrosis of the hepatic parenchyma.

performed the abovementioned dye leak test again and found that there was no leak at the repair site. Multiple abdominal drains were inserted at the sites of the LLS necrosectomy and jejunal limb repair. The pathology report showed complete necrosis of the liver (Fig. 8).

The patient recovered uneventfully, but a bile leak developed at five days after the necrosectomy (Fig. 9). We presumed that this bile leak was associated with failure

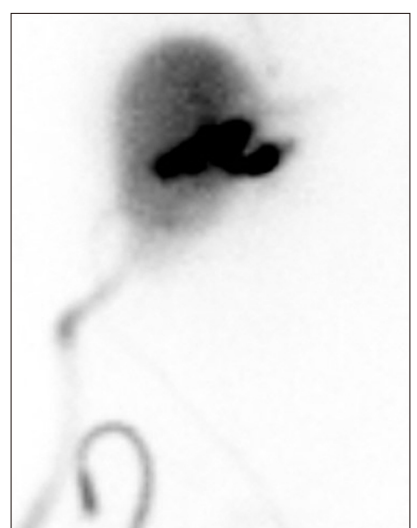

$30 \min$ ANT

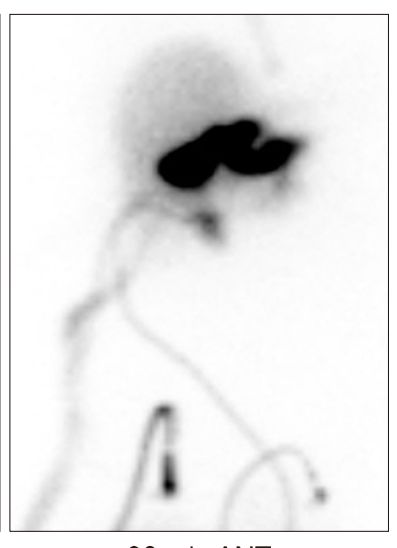

$90 \min$ ANT
Fig. 9. Postoperative hepatobiliary scintigraphy taken ten days after necrosectomy showed major bile leak.

of the repair of the partially opened jejunal limb. We decided to wait until development of heavy adhesion with maintenance of drainage of the bile leak and thereafter to do stepwise removal of the drains with induction of gradual leak site occlusion. Thus, we planned to wait for two months after surgery, and she was discharged with keeping one abdominal drain at three weeks after the necrosectomy (Fig. 10A, B). She was observed for five weeks at the outpatient clinic (Fig. 10C) and was readmitted for drain removal. At two months after the necrosectomy, the 

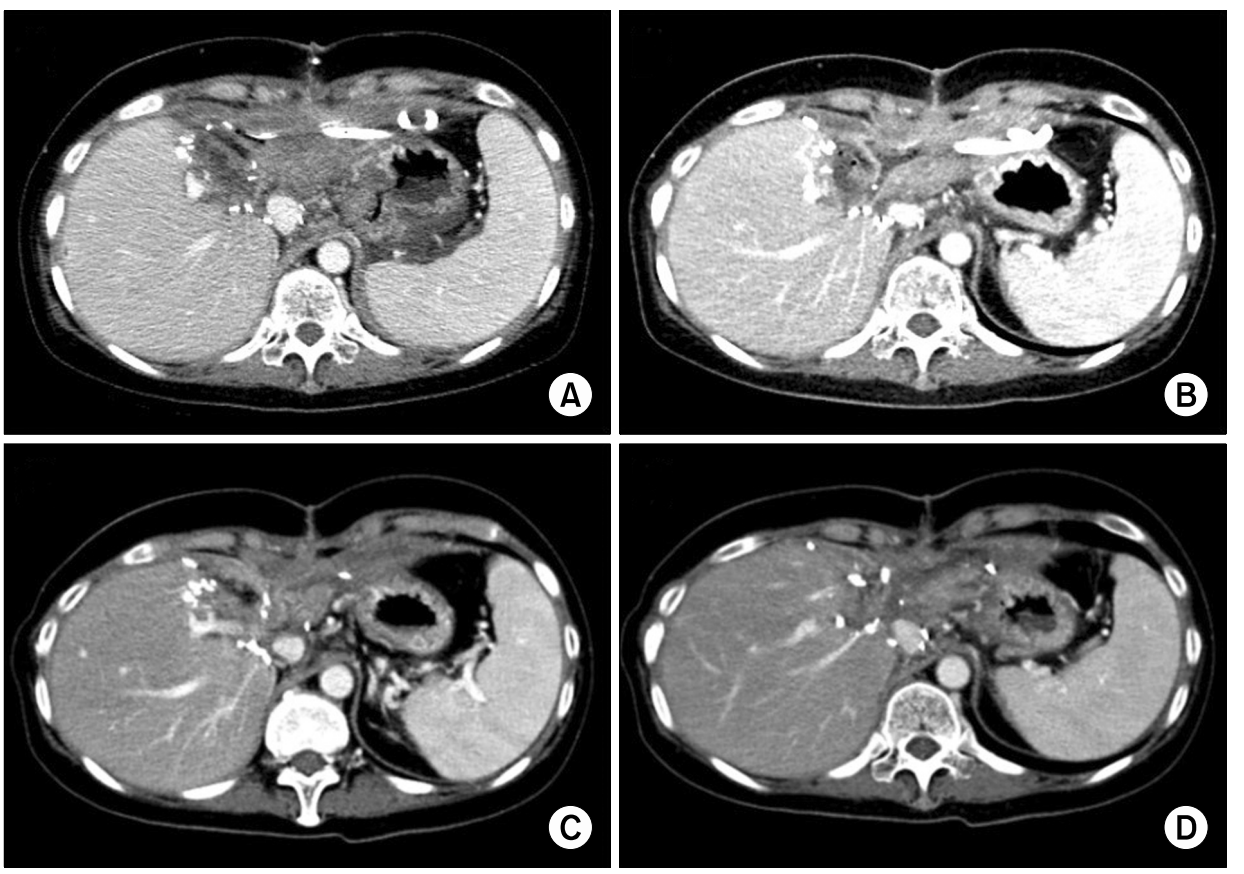

Fig. 10. Radiologic finding showing resolution process of bile leak. Computed tomography scans were taken at one week (A), two weeks (B), six weeks (C) and nine weeks (D) after the necrosectomy.

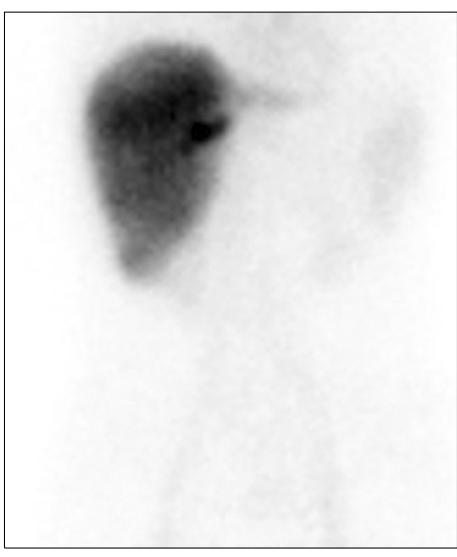

$5 \min$ ANT

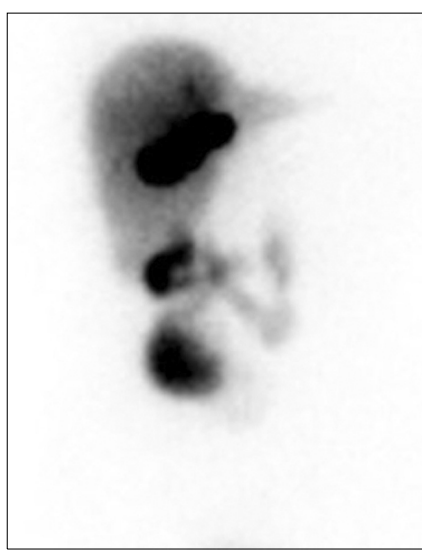

$30 \min$ ANT

Washout ratio $=90.5 \%$

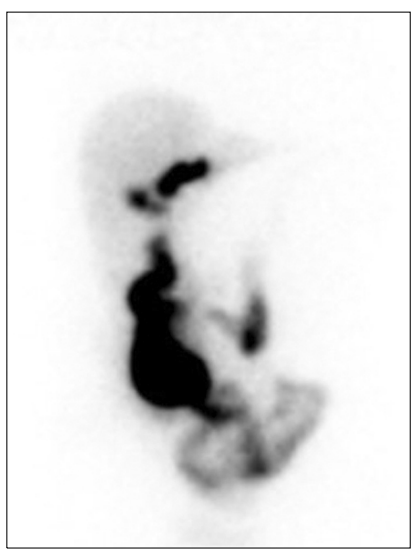

$60 \min$ ANT

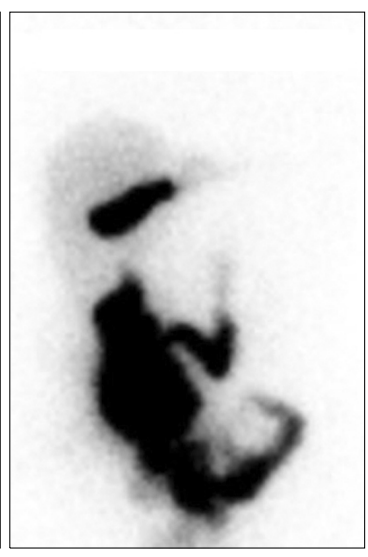

$90 \min$ ANT

Fig. 11. Postoperative hepatobiliary scintigraphy taken two months after necrosectomy showed no bile leak.

last abdominal drain was successfully removed (Fig. 10D), and no complications developed at all (Fig. 11). Currently, she is doing well without any physical discomfort four months after LLS necrosectomy. She will be followed up regularly for ten years after the initial cancer surgery.

\section{DISCUSSION}

Resection of one liver half after right-left separation of the liver has been rarely required in special situations, such as intrahepatic tumor recurrence localized at the one liver half or severe ischemic necrosis because of serious vascular complications. Our present case belongs to the latter indication, but its incidence is extremely low. However, the primary reason for our presenting this case is that secure transection and repair of the intervening jejunal limb between the right and left liver halves is technically demanding, and our technical skills learned from this case will be helpful for other similar situations.

In this case, the inflow and outflow vessels of the LLS were totally occluded because of blunt abdominal trauma requiring duodenal closure and diversion surgery, which finally led to total necrosis of the LLS parenchyma. The 
amount of hepatic parenchymal necrosis was too large to be resorbed spontaneously, so we decided to do surgical removal before development of life-threatening infectious complications. The vascular structures within the necrotic LLS were already occluded, but we did careful identification and confirmed ligation of every intrahepatic vascular stump to prevent accidental bleeding. However, hepaticojejunostomy to the LLS was widely disrupted and heavily adhered to the adjacent structures, thus it was not possible to identify the contour of the intervening jejunal limb between the right hemiliver and LLS.

To identify the intervening jejunal limb, we used two methods. The first was a frozen section biopsy of the disrupted luminal structure, by which it was proven to be mucosa of the small bowel. This finding was a direct evidence that the intervening jejunal limb was disrupted. The second was injection of dye solution into the afferent jejunal limb with temporary distal clamping. The injected dye solution was drained from the injured intervening jejunal limb, thus this procedure provided valuable information on the repair site of the jejunal limb and enabled us to check the status of the bile leak after primary repair.

The injured intervening jejunal limb was securely repaired with primary sutures and heavily covered with absorbable mesh and fibrin glue during the surgery, but bile leak developed after five days, probably because of delayed repair failure of the injured jejunal limb. This type of bile leak was different from that after hepatic transection. The latter leak is usually caused by proximal transection of the small bile ducts, so the bile leak usually continues until noticeable atrophy of the involved hepatic parenchyma and heavy adhesion at the leaking points develop. ${ }^{6-8}$ In contrast, the former leak was a distal-end leak caused by the partially opened jejunal limb, so the heavy adhesion around the leaking points would make the bile leak stop. We coped with the bile leak by means of long-standing waiting until heavy adhesion developed, maintaining drainage of the bile leak, and stepwise removal of the drain with induction of leak site occlusion. This procedure is very similar to that used for postoperative pancreatic leak after pancreatoduodenectomy. ${ }^{9}$ Based on our experience regarding major bile leak after hepatectomy, we learned that a two-month waiting period is necessary to induce heavy adhesion to block bile leak. Thus, we planned to wait for two months after surgery and successfully removed the last abdominal drain.

The extent of hepatic resection during the initial surgery was a kind of hepatic parenchyma-preserving surgery for perihilar cholangiocarcinoma. ${ }^{1-3,10}$ Major hepatectomy has definite advantages from the viewpoint of surgical oncology, but operative risk increases. This patient had perihilar cholangiocarcinoma of papillary growth, which was compatible to Bismuth-Corlette type IV. Considering the tumor spreading patterns of papillary tumors, hemihepatectomy occasionally resulted in microscopically tumor-positive bile duct resection margins. Segment IV+I resection is a classical extent of parenchyma-preserving hepatectomy for perihilar cholangiocarcinoma. The extent of hepatic resection in this patient was more extended to obtain tumor-free bile duct resection margins at the right liver half. If the right-sided bile duct margins had been tumor-positive, central bisectionectomy would be indicated to achieve R0 resection.

Our experience with this case suggests that an injury to the afferent jejunal limb requires an individualized treatment strategy including long-standing waiting with effective drainage until spontaneous healing develops. Our experience in this case appears to be theoretically matched with late staged resection of LLS following central hepatectomy and bile duct resection.

\section{ORCID}

Seul Gi Oh: https://orcid.org/0000-0001-5355-3969

Shin Hwang: https://orcid.org/0000-0002-9045-2531

Suhyeon Ha: https://orcid.org/0000-0001-8234-4170

Heewon Kim: https://orcid.org/0000-0001-8909-7352

Lee Na Ryu: https://orcid.org/0000-0002-2868-3355

\section{REFERENCES}

1. Miyazaki M, Ito H, Nakagawa K, Ambiru S, Shimizu H, Okaya $\mathrm{T}$, et al. Parenchyma-preserving hepatectomy in the surgical treatment of hilar cholangiocarcinoma. J Am Coll Surg 1999; 189:575-583.

2. Kawarada Y, Isaji S, Taoka H, Tabata M, Das BC, Yokoi H. $\mathrm{S} 4 \mathrm{a}+\mathrm{S} 5$ with caudate lobe (S1) resection using the Taj Mahal liver parenchymal resection for carcinoma of the biliary tract. J Gastrointest Surg 1999;3:369-373.

3. Hwang S, Moon DB, Park EH, Kim MH, Lee YJ, Lee SG. $\mathrm{S} 4 \mathrm{a}+\mathrm{S} 5$ with caudate lobe (S1) resection as a parenchyma-preserving liver resection for a patient with type IIIb hilar bile duct cancer. J Korean Surg Soc 2003;64:515-520.

4. Song GW, Lee SG, Moon DB, Ahn CS, Hwang S, Kim KH, 
et al. Dual-graft adult living donor liver transplantation: an innovative surgical procedure for live liver donor pool expansion. Ann Surg 2017;266:10-18.

5. Lu CH, Chen TY, Huang TL, Tsang LL, Ou HY, Yu CY, et al. Regeneration and outcome of dual grafts in living donor liver transplantation. Clin Transplant 2012;26:E143-E148.

6. Hwang S, Yoon SY, Jung SW, Namgoong JM, Park GC, Gwon DI, et al. Therapeutic induction of hepatic atrophy for isolated injury of the right posterior sectoral duct following laparoscopic cholecystectomy. Korean J Hepatobiliary Pancreat Surg 2011;15: 189-193.

7. Hwang S, Lee SG, Lee YJ, Ha TY, Ko GY, Song GW. Delayed-onset isolated injury of the right posterior segment duct after laparoscopic cholecystectomy: a report of hepatic segmental atrophy induction. Surg Laparosc Endosc Percutan Tech 2007;
17:203-205.

8. Hwang S, Park GC, Ha TY, Ko GY, Gwon DI, Choi YI, et al. Hepatic parenchymal atrophy induction for intractable segmental bile duct injury after liver resection. Hepatogastroenterology 2012;59:866-868.

9. Yoon YI, Hwang S, Cho YJ, Ha TY, Song GW, Jung DH. Therapeutic effect of trans-drain administration of antibiotics in patients showing intractable pancreatic leak-associated pus drainage after pancreaticoduodenectomy. Korean J Hepatobiliary Pancreat Surg 2015;19:17-24.

10. Lee SG, Song GW, Hwang S, Ha TY, Moon DB, Jung DH, et al. Surgical treatment of hilar cholangiocarcinoma in the new era: the Asan experience. J Hepatobiliary Pancreat Sci 2010;17: 476-489. 